\title{
In the Workshop after I Read My Poem Aloud . Don Colburn
}

All at once everyone in the room says nothing. They continue doing this and I begin to know it is not because they are dumb. Finally

the guy from the Bay Area who wears his chapbook on his sleeve says he likes the poem a lot but can't really say why and silence

starts all over until someone says she only has a couple of teeny suggestions such as taking out the first three stanzas along with

all modifiers except "slippery" and "delicious" in the remaining four lines. A guy who hasn't said a word in three days says

he too likes the poem but wonders why it was written and since I don't know either and don't even know if I should

I'm grateful there's a rule I can't say anything now. Somebody I think it's the shrink from Seattle

says the emotion is not earned and I wonder when is it ever. The woman on my left who just had a prose poem in Green Thumbs \& Geoducks says the opening stanza is unbelievable and vindication comes for a sweet moment until I realize she means unbelievable. 
But I have my defenders too and the MFA from Iowa the one who thinks the you is an I and the they a we and the then a now

wants to praise the way the essential nihilism of the poem's occasion serves to undermine the formality of its diction. Just like your comment

I say to myself. Another admires the zenlike polarity of the final image despite the mildly bathetic symbolism of sheep droppings and he loves how

the three clichés in the penultimate stanza are rescued by the brazen self-exploiting risk. The teacher asks what about the last line and the guy with the chapbook volunteers it suits the poem's unambitious purpose though he has to admit it could be worded somewhat differently. 